ASTHMA

\title{
Lung function decline in asthma: association with inhaled corticosteroids, smoking and sex
}

\author{
A Dijkstra, J M Vonk, H Jongepier, G H Koppelman, J P Schouten, N H T ten Hacken, \\ W Timens, D S Postma

See end of article for authors' affiliations

.....................

Correspondence to: Dr D S Postma

Department of

Pulmonology, University Medical Center

Groningen, Hanzeplein 1

P O Box 30.001, 9700 RB

Groningen, The

Netherlands; d.s.postma@

int.umcg.nl

Received

20 December 2004

Accepted

2 November 2005

Published Online First

24 November 2005
Background: Inhaled corticosteroids (ICS) provide short term benefits in asthma but the long term effects are still unknown.

Methods: 281 patients diagnosed with moderate to severe asthma in 1963-75 were re-examined in 1991-9. Information was collected on forced expiratory volume in 1 second $\left(\mathrm{FEV}_{1}\right)$, bronchial hyperresponsiveness, atopy, smoking, use and dosage of oral and ICS. Patients were included in the analyses if they had at least three $\mathrm{FEV}_{1}$ measurements during two consecutive years after the age of 30 and used ICS during follow up.

Results: Analyses were performed on 122 patients. During a median follow up period of 23 years, 71 men and 51 women had on average 37 and 40 individual $\mathrm{FEV}_{1}$ measurements, respectively. Linear mixed effect models showed that men had a mean annual decline in $\mathrm{FEV}_{1}$ of $20.6 \mathrm{ml} /$ year less after ICS initiation than before $(p=0.011)$, and in women the decline in $\mathrm{FEV}_{1}$ was $3.2 \mathrm{ml} /$ year less $(p=0.73)$. In individuals with $<5$ pack years of smoking the decline in $\mathrm{FEV}_{1}$ was $36.8 \mathrm{ml} /$ year less after ICS institution in men $(p=0.0097)$ and $0.8 \mathrm{ml} /$ year less in women $(p=0.94)$, the difference between the sexes being significant $(p=0.045)$. These effects were not observed in those with $\geqslant 5$ pack years smoking. A higher daily dose of ICS was associated with a smaller decline in $\mathrm{FEV}_{1}$ in men $(p=0.006)$, an effect not observed in women. Conclusion: Treatment with ICS in adult patients with moderate to severe asthma was associated with a reduction in the decline in $\mathrm{FEV}_{1}$ over a 23 year follow up period in men who had smoked $<5$ pack years. This effect was dose dependent and was not present in women or in men with $\geqslant 5$ pack years of smoking at follow up. The lack of effect of ICS on the decline in $\mathrm{FEV}_{1}$ in women needs further study.
A sthma is a chronic inflammatory respiratory disease with variable and fully reversible airway obstruction in most patients. It is generally held that asthma is a benign disease in which persistent airway obstruction is virtually absent. Nevertheless, cross sectional studies show that children and adults with asthma have on average a lower lung function than non-asthmatics, especially in the case of persistent asthma symptoms..$^{1-5}$ Moreover, a substantially greater loss in lung function over time has been reported in adult asthma. ${ }^{16-9}$ Fixed airway obstruction and an accelerated decline in lung function may stem from structural airway changes that accompany the underlying airway wall inflammation in asthma, generally known as airway remodelling. ${ }^{10-13}$ Virtually all short term studies (weeks to a few years) have shown that inhaled corticosteroids benefit patients with chronic persistent asthma by decreasing airway inflammation, improving lung function, and reducing symptoms and airway hyperresponsiveness. However, no studies have been performed to determine whether inhaled corticosteroids also slow down progressive loss of lung function over time.

Some factors have been suggested to affect the steroid response in asthma. One study showed women with asthma to have less short term benefit from inhaled corticosteroid treatment than men, ${ }^{14}$ compatible with the observed higher prevalence of severe asthma in women. ${ }^{15}$ Furthermore, persistent active asthma has a negative impact on the annual decline in forced expiratory volume in 1 second $\left(\mathrm{FEV}_{1}\right)$ in women but not in men. ${ }^{2}$ Smoking has also been suggested to have a negative influence on the steroid response in asthma. ${ }^{16-18}$

This study was undertaken to assess whether inhaled corticosteroids may, in addition to their well established beneficial short term effects, slow down the progressive loss in lung function in men and women, and to assess the effect of cigarette smoking on these effects of inhaled corticosteroids. We evaluated lung function data over a median follow up period of 23 years in a population of objectively diagnosed asthmatics.

\section{METHODS}

\section{Study population}

Two hundred and eighty one patients diagnosed with symptomatic asthma who attended Beatrixoord, a regional referral centre (Haren, the Netherlands), in 1963-75 were evaluated. At initial testing all were characterised using a standardised clinical protocol as previously described; ${ }^{19} 20$ all were younger than 45 years and showed bronchial hyperresponsiveness to histamine $\left(30\right.$ seconds method; $\mathrm{PC}_{20}$ $\leqslant 32 \mathrm{mg} / \mathrm{ml}$ ). ${ }^{21}$ In 1991-9 all were re-examined using the same methodology.

Sixty eight subjects were excluded from the longitudinal analyses on lung function decline because they only had $\mathrm{FEV}_{1}$ data before the age of 30 or an insufficient number of $\mathrm{FEV}_{1}$ measurements after age 30 . Twelve had missing lung function records, five had incomplete or unknown data on smoking history, 67 had never used inhaled corticosteroids, and seven had only intermittent use of inhaled corticosteroids. Data for the remaining 122 individuals were included in the analyses on the effect of inhaled corticosteroids on decline in lung function.

The medical ethics committee of the University Hospital Groningen approved the study and written informed consent was obtained from all participants.

\section{Clinical assessment}

The initial characterisation (1963-75) included assessment of bronchial hyperresponsiveness to histamine, ${ }^{21}$ allergen skin 
tests, lung function, reversibility 30 minutes after intramuscular injection of $25 \mathrm{mg}$ thiazinamium (a potent anticholinergic drug with antihistamine properties), and peripheral blood eosinophil counts. ${ }^{19}$ At re-examination in 1991-9, measurements were repeated using the same methodology. Reversibility was tested 20 minutes after inhalation of $800 \mu \mathrm{g}$ salbutamol (albuterol). In addition, total serum IgE levels were measured either by solid phase immunoassay (Pharmacia, Uppsala, Sweden) or enzyme linked fluorescent assay (Mini Vidas, Biomerieux Inc, Marcy, France) and participants answered a modified British Medical Society Respiratory Questionnaire. ${ }^{22}$ Before testing, participants had no exacerbation and had not used oral corticosteroids during the previous 6 weeks. Maintenance medication was stopped for the appropriate time. ${ }^{19}$

After initial testing, subjects generally had routine checkups for their asthma at least once a year. Data on lung function and corticosteroid use during check-ups were extracted from the medical records. Lung function was tested with a water sealed spirometer throughout the follow up period (Lode Spirograph D53, Lode Instruments, Groningen, the Netherlands). Lung function data during hospital admissions, asthma exacerbations, or pregnancies were not used.

The dose of inhaled corticosteroids was calculated to an equivalent daily dose of beclomethasone-that is, $500 \mu \mathrm{g}$ fluticasone, $1000 \mu \mathrm{g}$ budesonide, and $500 \mu \mathrm{g}$ budesonide via Turbuhaler being equipotent to $1000 \mu \mathrm{g}$ beclomethasone. ${ }^{23}$

\section{Statistical analyses}

Linear mixed effect models on $\mathrm{FEV}_{1}$ were used to investigate the effect of the use of inhaled corticosteroids on the annual decline in $\mathrm{FEV}_{1}{ }^{24}$ The age of 30 was the starting point of the analyses since the maximum lung function level would be achieved before that age and lung function is considered to be in the decline phase. ${ }^{25}$ Following the methodology described by Naumova et al, ${ }^{26}$ time was defined as the time relative to the start of inhaled corticosteroid treatment in years. Separate estimations of the annual $\mathrm{FEV}_{1}$ decline and $\mathrm{FEV}_{1}$ levels (i.e. intercepts) were made for the periods before and after the start of inhaled corticosteroid treatment by including the variables time, inhaled corticosteroid use, and their interaction. Furthermore, individual variations in these declines and intercepts were accounted for by estimating the

\begin{tabular}{|c|c|c|}
\hline Characteristics & $\begin{array}{l}\text { Excluded } \\
\text { subjects } \\
(\mathrm{n}=159)\end{array}$ & $\begin{array}{l}\text { Included } \\
\text { subjects } \\
\text { ( } n=122)\end{array}$ \\
\hline Males (\%) & $99(62)$ & $\begin{array}{l}71(58) \\
6(2-2)\end{array}$ \\
\hline $\begin{array}{l}\text { Mean daily dose of inhaled } \\
\text { corticosteroids }(\mu \mathrm{g} / \text { day })^{*} \\
\text { Initial testing }\end{array}$ & - & $720(426-1116)$ \\
\hline Age (years) & $20(15-28)$ & $28(21-37)$ \\
\hline $\mathrm{FEV}_{1} \%$ predicted post BD (\%) & $94(82-104)$ & $85(68-97)$ \\
\hline BHR $\leqslant 16.0 \mathrm{mg} / \mathrm{ml}(\%)$ & 87 & 87 \\
\hline$\geqslant 1$ positive skin test (\%) & & 87 \\
\hline Blood eosinophils $\left(\times 10^{6} / 1\right)$ & $385(220-539)$ & $330(220-528)$ \\
\hline Reversibility (\% predicted) & $21(14-31)$ & $25(17-33)$ \\
\hline $\begin{array}{l}\text { Smoking } \\
\text { Pack years smoking }\end{array}$ & $0.0(0.0-2.9)$ & $0.1(0-5.6)$ \\
\hline Non/ex/current smokers (\%) & $50 / 5 / 45$ & $49 / 6 / 45$ \\
\hline
\end{tabular}

Data are presented as median values (interquartile range) unless stated otherwise.

$B H R$, bronchial hyperresponsiveness; post $B D$, after administration of bronchodilator.

${ }^{*}$ Calculated for individuals who ever used inhaled corticosteroids only. Differences tested by $\chi^{2}$ test (categorical variables) or Mann-Whitney U test (continuous variables). random effects for these variables. Effect modification by sex was incorporated in the model by adding the interaction between time, inhaled corticosteroid use, and sex. Other explanatory variables in the model were height (centred at $1.75 \mathrm{~m})$, first available $\mathrm{FEV}_{1}$ after age $30\left(\mathrm{FEV}_{1}\right.$ centred at $2.8 \mathrm{l}$, called " $\mathrm{FEV}_{1}$ at age $30^{\prime \prime}$ ), and their interaction with time, pack years of smoking, and oral corticosteroid use. The latter two variables were time varying. Since including the level of the $\mathrm{FEV}_{1}$ at age 30 and their interaction with time could introduce bias due to regression to the mean, random effects were also estimated for these variables. The results of these analyses indicated that there was no regression to the mean bias-that is, the estimates of the variables in the model did not change and the model fit was not better and therefore the results are presented without these random effects. Several within-subject correlation structures were investigated but none of these gave a better fit than the independent within-subject correlation. To investigate possible effect modification by smoking on the effect of inhaled corticosteroid use on $\mathrm{FEV}_{1}$ decline, the analysis was stratified by pack years of smoking ( $<5$ and $\geqslant 5$ pack years) at reexamination. Additional potential risk factors were introduced in the model one at a time-that is, severity of bronchial hyperresponsiveness to histamine at initial testing, number of blood eosinophils, atopy and reversibility (\% of predicted) at initial testing and re-examination, total IgE at re-examination, age at introduction of inhaled corticosteroids, untreated period (time between the onset of symptoms and the first visit to Beatrixoord), and age at onset of symptoms.

To investigate whether the effect of inhaled corticosteroid use on the annual decline in $\mathrm{FEV}_{1}$ was dose dependent, subjects were divided into a low dose group $(<720 \mu$ g per day) and a high dose group ( $\geqslant 720 \mu \mathrm{g}$ per day) based on the median value of individually calculated mean daily doses of inhaled corticosteroids $(720 \mu \mathrm{g}$ per day). This grouping variable was then introduced in the model and separate slopes were fitted before and during the use of inhaled corticosteroids for the two dose groups. To avoid a four-way interaction and the difficulties in interpreting this (dose group * time * inhaled corticosteroid use * sex), analyses were stratified by sex.

To be able to make valid interpretations of the results, individual $\mathrm{FEV}_{1}$ series had to meet basic criteria to be included in the analyses. Firstly, subjects who never used inhaled corticosteroids were excluded. Secondly, subjects had to have three or more $\mathrm{FEV}_{1}$ measurements over a period of at least 2 years in which they did not use inhaled corticosteroids and/or three or more $\mathrm{FEV}_{1}$ measurements over a period of at least 2 years in which they did use inhaled corticosteroids. In subjects who had measurements both with and without inhaled corticosteroids, the earliest measurements should be without inhaled corticosteroids and the later with inhaled corticosteroids. If subjects started using inhaled corticosteroids but had discontinued the use of inhaled corticosteroids after a few years, all measurements made after the discontinuation were discarded, even if they started again. In subjects who had sufficient measurements without inhaled corticosteroids but fewer than three measurements with inhaled corticosteroids or during less than 2 years, only the measurements without inhaled corticosteroids were included in the model.

All calculations were conducted in S-plus 2000 (Insightful Corporation, Seattle, WA, USA).

\section{RESULTS}

\section{Baseline characteristics}

The characteristics of the included and excluded individuals are shown in table 1. Included participants were older, were 
Table 2 Characteristics of men and women in study

\begin{tabular}{|c|c|c|}
\hline Characteristics & $\begin{array}{l}\text { Men } \\
(n=71)\end{array}$ & $\begin{array}{l}\text { Women } \\
(n=51)\end{array}$ \\
\hline $\begin{array}{l}\text { Age of onset of symptoms (years) } \\
\text { Untreated period (years) }\end{array}$ & $\begin{array}{l}6(2-22) \\
14(4-22)\end{array}$ & $\begin{array}{l}6(3-21) \\
16(9-25)\end{array}$ \\
\hline $\begin{array}{l}\text { Age at start of inhaled } \\
\text { corticosteroids (years) }\end{array}$ & $40(34-48)$ & $45(35-53)$ \\
\hline $\begin{array}{l}\text { Mean daily dose of inhaled } \\
\text { corticosteroids }(\mu \mathrm{g} / \text { day })^{*}\end{array}$ & $794(527-1129)$ & $618(400-1114)$ \\
\hline $\begin{array}{l}\text { Period of inhaled corticosteroid } \\
\text { use (years) }\end{array}$ & $13.6(7.0-19.4)$ & $14.0(8.5-20.7)$ \\
\hline $\begin{array}{l}\text { Duration of inhaled corticosteroid } \\
\text { use (years of } 100 \mu \mathrm{g} \text { use daily) }\end{array}$ & $\begin{array}{l}110.1(47.7- \\
165.9)\end{array}$ & $\begin{array}{l}88.6(46.4- \\
155.9)\end{array}$ \\
\hline \multicolumn{3}{|l|}{ Initial testing } \\
\hline Age (years) & $27(21-34)$ & $30(24-37)$ \\
\hline $\mathrm{FEV}_{1} \%$ predicted pre $\mathrm{BD}(\%)$ & $56(45-71)$ & $56(39-69)$ \\
\hline $\mathrm{FEV}_{1} \%$ predicted post $\mathrm{BD}(\%)$ & $85(66-97)$ & $87(68-97)$ \\
\hline BHR $\leqslant 16.0 \mathrm{mg} / \mathrm{ml}(\%)$ & 86 & 88 \\
\hline$\geqslant 1$ positive skin test (\%) & 86 & 88 \\
\hline Blood eosinophils $\left(\times 10^{6} / \mathrm{l}\right)$ & $341(237-534)$ & $280(215-481)$ \\
\hline Reversibility (\% predicted) & $24(18-32)$ & $28(17-33)$ \\
\hline \multicolumn{3}{|l|}{ Smoking } \\
\hline Pack years smoking & $2.4(0-7.2) \dagger$ & $0(0-0.5)$ \\
\hline Non/ex/current smokers (\%) & $34 / 10 / 56 \dagger$ & $71 / 0 / 29$ \\
\hline \multicolumn{3}{|l|}{ Re-examination } \\
\hline Age (years) & $53(46-59)$ & $57(50-62)$ \\
\hline $\mathrm{FEV}_{1} \%$ predicted pre $\mathrm{BD}(\%)$ & $57(42-74)$ & $61(39-81)$ \\
\hline $\mathrm{FEV}, \%$ predicted post $\mathrm{BD}(\%)$ & $70(54-85) \pm$ & $78(62-95)$ \\
\hline BHR $\leqslant 16.0$ mg/ml (\%) & 88 & 85 \\
\hline$\geqslant 1$ positive skin test (\%) & 77 & 73 \\
\hline Blood eosinophils $\left(\times 10^{6} / \mathrm{I}\right)$ & $130(70-220)$ & $132(66-220)$ \\
\hline Reversibility (\% predicted) & $12(8-16) \S$ & $15(9-21)$ \\
\hline Total lgE (IU/I) & $96(27-442) \oplus$ & $47(25-193)$ \\
\hline Total lgE $\geqslant 120 \mathrm{IU} / \mathrm{I}(\%)$ & 46 & 32 \\
\hline \multicolumn{3}{|l|}{ Smoking } \\
\hline Pack years smoking & $8.4(0.3-16.9) \dagger$ & $0(0-3.6)$ \\
\hline Non/ex/current smokers (\%) & $24 / 47 / 30+$ & $71 / 20 / 10$ \\
\hline
\end{tabular}

Data are presented as median values (interquartile range) unless stated otherwise.

$B H R$, bronchial hyperresponsiveness; pre $B D$, before administration of bronchodilator; post $\mathrm{BD}$, after administration of bronchodilator.

${ }^{*}$ Calculated for individuals who ever used inhaled corticosteroids only. Differences tested by $\chi^{2}$ test (categorical variables) or Mann-Whitney U test (continuous variables). Significant difference between males and females: $\uparrow p<0.0001 ; \neq p=0.035 ; \xi p=0.018 ; \uparrow p=0.040$. less frequently atopic, and had (as expected) lower FEV 1 and higher reversibility at initial testing. The median (interquartile range) duration of follow up of the included group was 23.3 (15-29) years. Table 2 shows the characteristics of male and female participants.

There were $4663 \mathrm{FEV}_{1}$ measurements, the median number of measurements per individual being 37 (22-48) in men and $40(24-54)$ in women. The median length of the period without inhaled corticosteroids was 9.8 years (6-19) and the median length with inhaled corticosteroids was 13.8 years (8-20). There was a predominance of smoking in men at baseline and at re-examination, otherwise men and women had similar clinical characteristics at baseline. At reexamination, women had a significantly higher $\mathrm{FEV}_{1} \%$ predicted post bronchodilator, a higher degree of reversibility, and a lower total IgE level than men. There was no significant difference between men and women with respect to the age at which inhaled corticosteroids were initiated, the daily dose, or the cumulative dose of inhaled corticosteroids used.

\section{Longitudinal change in lung function}

Median $\mathrm{FEV}_{1}$ at the start of the study (age 30 years) was 2.8 litres. The mean (95\% CI) annual decline in $\mathrm{FEV}_{1}$ was 36.6 (23.3 to 50.0) ml/year for a man with an $\mathrm{FEV}_{1}$ of 2.8 litres before institution of inhaled corticosteroids. Subjects who never used inhaled corticosteroids had an annual decline in $\mathrm{FEV}_{1}$ of 12.5 (3.7 to 21.2 ) ml/year. The difference between subjects who never used inhaled corticosteroids and those who later started inhaled corticosteroids was significant $(\mathrm{p}=0.0001)$, the latter group having a more rapid decline.

\section{Effect of sex}

The introduction of inhaled corticosteroids was associated with a significant reduction in the mean annual decline in $\mathrm{FEV}_{1}$ of $12.9(1.0$ to 24.8$) \mathrm{ml} /$ year $(p=0.033)$. When comparing the sexes, the mean annual decline in $\mathrm{FEV}_{1}$ was similar in men and women before introduction of inhaled corticosteroids: 36.6 (23.3 to 50.0) and 24.7 (9.1 to 40.3$) \mathrm{ml} /$ year, respectively ( $p=0.25$, fig 1$)$. After institution of inhaled corticosteroids men had a significantly smaller decline in
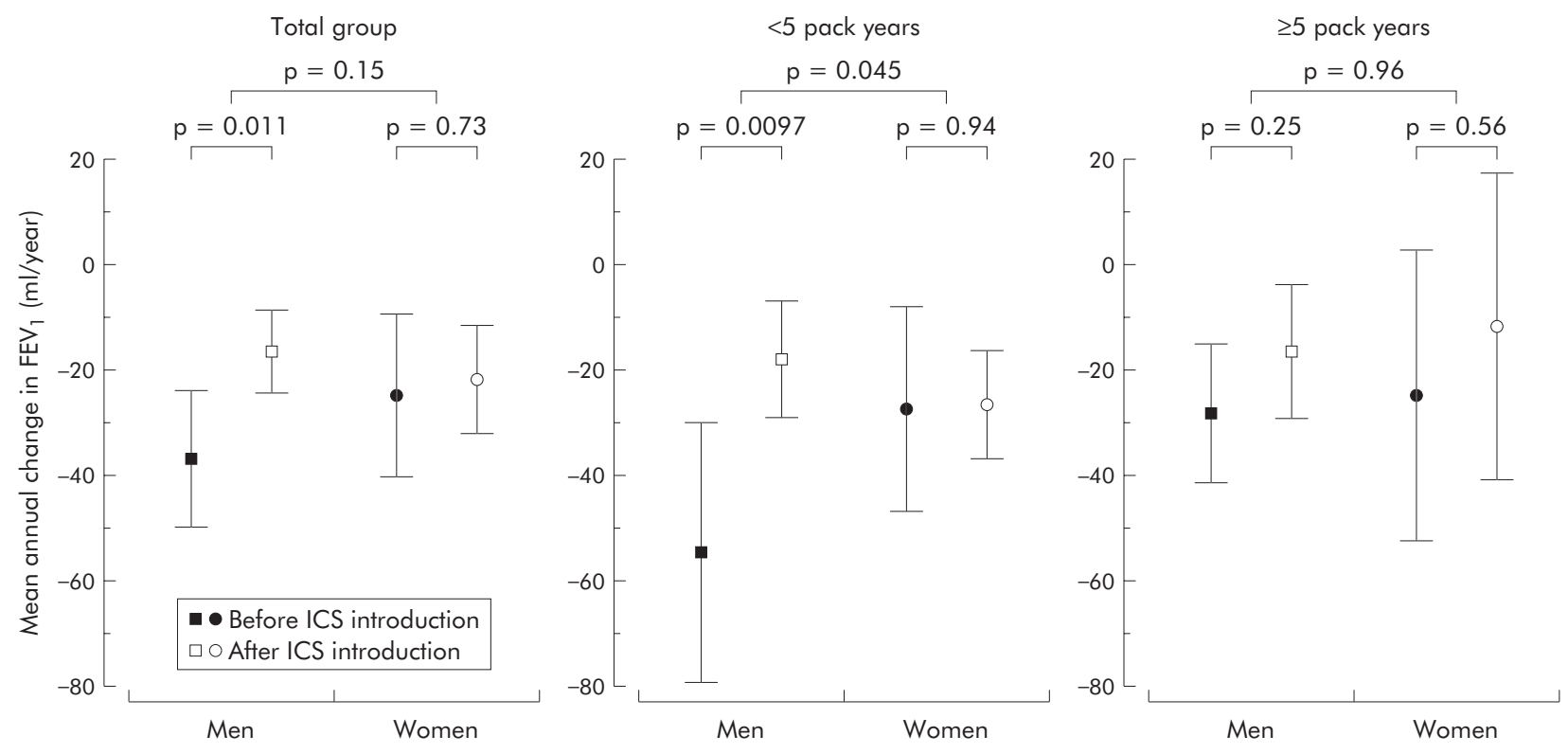

Figure 1 Mean annual change in $\mathrm{FEV}_{1}$ in $\mathrm{ml} /$ year (with $95 \%$ confidence interval) for men and women before and after starting treatment with inhaled corticosteroids (ICS). Data were corrected for level of $\mathrm{FEV}_{1}$ at age 30 (centred at $2.8 \mathrm{l}$ ), height (centred at $1.75 \mathrm{~m}$ ), pack years smoking, and oral corticosteroid use. Significant differences are shown before and after the introduction of inhaled corticosteroids in men and women, and in the effect of inhaled corticosteroids in men and women. 


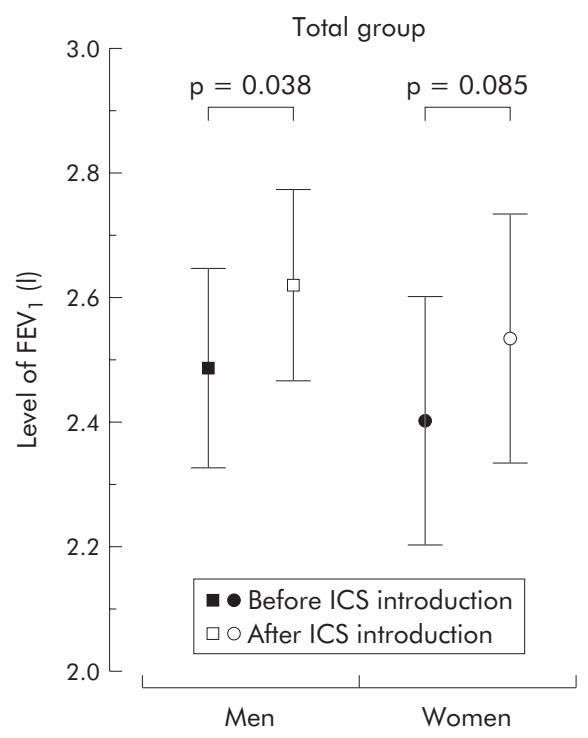

Figure 2 Initial improvement in lung function in men and women before and after introduction of inhaled corticosteroids (ICS). Corrected for level of $\mathrm{FEV}_{1}$ at age 30 (centred at $2.8 \mathrm{I}$ ), height (centred at $1.75 \mathrm{~m}$ ), pack years smoking, and oral corticosteroid use.

$\mathrm{FEV}_{1}$ than before ( 16.1 (8.0 to 24.1 ) $\mathrm{ml} /$ year; $\mathrm{p}=0.011$ ) while in women there was no significant difference (21.5 (11.3 to 31.7) $\mathrm{ml} /$ year; $\mathrm{p}=0.73$ ). The effect of starting treatment with inhaled corticosteroids on the decline in $\mathrm{FEV}_{1}$ was not significantly different between men and women, the difference in change in $\mathrm{FEV}_{1}$ decline between the two sexes being $17.4(-41.4$ to 6.5$) \mathrm{ml} /$ year $(\mathrm{p}=0.15)$.

The level of $\mathrm{FEV}_{1}$ improved after the start of inhaled corticosteroids by 132.8 (7.1 to 258.5$) \mathrm{ml}$ in men $(\mathrm{p}=0.038)$ and $132.3(-18.4$ to 283.1$) \mathrm{ml}$ in women $(\mathrm{p}=0.085$, fig 2$)$.

\section{Effect of smoking}

The decline in $\mathrm{FEV}_{1}$ before the start of inhaled corticosteroids was not significantly different between men and women with $<5$ pack years smoking at re-examination: 54.4 (29.5 to 79.2) and 27.3 ( 7.6 to 46.9 ) $\mathrm{ml} /$ year, respectively $(\mathrm{p}=0.096$, fig $\mathrm{l})$. In men with $<5$ pack years smoking, the mean decline in $\mathrm{FEV}_{1}$ changed from 54.4 (29.5 to 79.2 ) $\mathrm{ml} /$ year to 17.7 (6.5 to 28.7) $\mathrm{ml} /$ year after the start of inhaled corticosteroids, the difference of $36.8 \mathrm{ml} /$ year being significant $(\mathrm{p}=0.0097)$. In women the values were 27.3 ( 7.6 to 46.9 ) $\mathrm{ml} /$ year and 26.5 (15.8 to 37.1 ) ml/year respectively; this difference was not significant. Inhaled corticosteroids reduced the decline in $\mathrm{FEV}_{1}$ significantly more in men than in women (by 36.0 (0.9 to 71.0$) \mathrm{ml} /$ year more in men $(\mathrm{p}=0.045))$. This positive effect of inhaled corticosteroids was not observed in individuals with $\geqslant 5$ pack years smoking. The decline in $\mathrm{FEV}_{1}$ before and after institution of inhaled corticosteroids was 27.8 ( 14.3 to 41.3 ) $\mathrm{ml} /$ year and 16.1 (3.3 to 28.9 ) $\mathrm{ml} /$ year in men, and 24.5 (3.1 to 52.0$) \mathrm{ml} / \mathrm{year}$ and 11.6 (17.7 to $41.0) \mathrm{ml} /$ year in women, respectively. The decline in $\mathrm{FEV}_{1}$ before and after starting treatment with inhaled corticosteroids did not differ between men and women (1.1 $(-46.4$ to 48.5 ) $\mathrm{ml} /$ year; $\mathrm{p}=0.96$ ).

\section{Dose-response effect of inhaled corticosteroids}

There was no significant difference in $\mathrm{FEV}_{1}$ decline before and after institution of inhaled corticosteroids in men who used $<720 \mu \mathrm{g} /$ day (median daily dose used): 14.5 (-11.4 to $40.5) \mathrm{ml} /$ year before and 23.6 (11.8 to 35.3$) \mathrm{ml} /$ year after initiation of inhaled corticosteroids $(p=0.51$, fig 3$)$. In men who used $\geqslant 720 \mu \mathrm{g} /$ day the decline in $\mathrm{FEV}_{1}$ after introduction

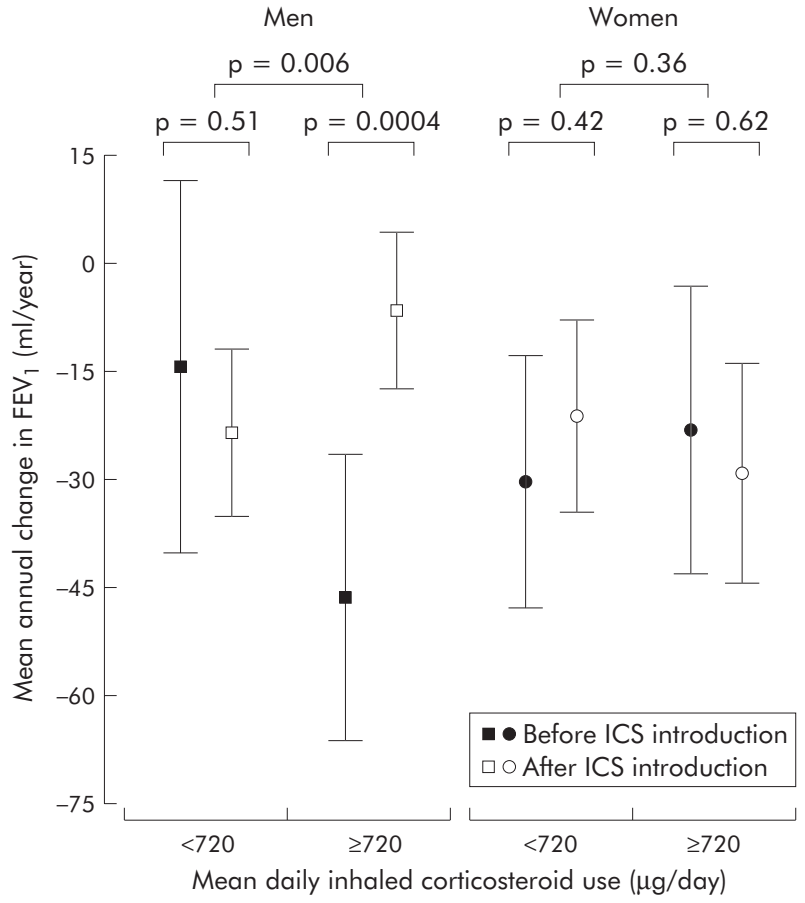

Figure 3 Mean annual change in $\mathrm{FEV}_{1}$ in $\mathrm{ml} /$ year (with $95 \%$ confidence interval) for men and women for low and high mean daily dosage of inhaled corticosteroid use $(<720$ and $\geqslant 720 \mu \mathrm{g} /$ day).

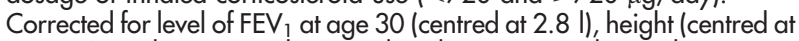
$1.75 \mathrm{~m}$ ), pack years smoking, and oral corticosteroid use. There were significant differences between before and after introduction of inhaled corticosteroids, and between low and high daily dosage of inhaled corticosteroid use in men and women.

of inhaled corticosteroids was $39.8 \mathrm{ml} / \mathrm{year}$ less than before introduction $(\mathrm{p}=0.0004)$. Men who used $\geqslant 720 \mu \mathrm{g} /$ day inhaled corticosteroids had significantly less deterioration in $\mathrm{FEV}_{\mathrm{l}}$ than men using $<720 \mu \mathrm{g} /$ day $(48.8 \mathrm{ml} / \mathrm{year}$ less decline; $p=0.006$, fig 3 ). This effect was not seen in women.

\section{Risk factors for lung function decline}

No additional association was observed with age at onset of symptoms, age at start of inhaled corticosteroids, untreated period, bronchial hyperresponsiveness at initial testing, number of blood eosinophils, total IgE levels, atopy, or reversibility (\% predicted).

\section{DISCUSSION}

We present the results of a 23 year follow up study in adult patients who had longstanding asthma at the time inhaled corticosteroids became available in the Netherlands (in 1974), and who had moderate to severe asthma. The results show that both men and women had a comparable decline in lung function before the institution of inhaled corticosteroids. In men the use of inhaled corticosteroids was significantly associated with a reduction in the annual decline in lung function, a finding not observed in women. The beneficial effect of inhaled corticosteroids was dose dependent and was not present in men with $>5$ pack years smoking.

We are aware that our study is observational in nature and that there is a possibility that the lack of significance of inhaled corticosteroids in women is a spurious effect. Can we, based on our observations, advise not to prescribe inhaled corticosteroids to women with asthma? Firstly, inhaled corticosteroids are beneficial to almost all asthmatics of both sexes by their well known short term (up to 3-5 years) 
improvement in lung function, an effect also observed in our study in both men and women. Moreover, inhaled corticosteroids improve symptoms, exacerbation rate, and quality of life in short term studies. Therefore, our study in no way implies that women should not be prescribed inhaled corticosteroids. However, given these short term beneficial effects, one cannot simply evaluate in a double blind randomised study whether inhaled corticosteroids prevent the decline in lung function in asthma over many years. Our data are therefore the best available long term data to date.

Our 23 year follow up study attempted to evaluate whether inhaled corticosteroids prevent lung function loss in asthma. We therefore had to exclude patients who had never used inhaled corticosteroids. We are aware that excluding these patients could lead to some unintended bias, but this group was not the aim of our cohort study. As expected, we found that those not using inhaled corticosteroids at all had better lung function at initial testing and a less rapid decline in $\mathrm{FEV}_{1}$ over time, probably because they had milder disease. Whether they would also have benefited from inhaled corticosteroids in the long term could not be addressed by our study.

Asthma is generally a benign disease. However, it is acknowledged that lung function may decline more rapidly than in healthy individuals, ${ }^{6}$ probably as a result of an ongoing chronic inflammatory airway disease. It is therefore of interest to assess whether anti-inflammatory agents may prevent accelerated loss in lung function. Double blind studies in mild to severe asthma have consistently shown their beneficial effects over short periods of time, ${ }^{1627}$ although some studies have failed to show this. ${ }^{28}$ Our study indicates that an accelerated loss in lung function may indeed occur in asthma which may be reduced by long term treatment with inhaled corticosteroids. Beneficial effects of inhaled steroids have been reported in newly diagnosed asthma with respect to lung function over longer periods of time. ${ }^{29}{ }^{30}$ Interestingly, we show that this treatment may also be of benefit in individuals with longstanding asthma. Previous (relatively) short term studies did not stratify for sex to assess whether women and men have different responses to inhaled corticosteroids. ${ }^{18} 28{ }^{30}$ Our study shows that the observed beneficial effect of this treatment with respect to long term decline in $\mathrm{FEV}_{1}$ is present in men but not in women with moderate to severe asthma. This is consistent with a recent double blind study in 52 asthmatics (26 placebo) which showed that bronchial hyperresponsiveness improved approximately threefold more in men than in women after 6 weeks of treatment with $2000 \mu \mathrm{g}$ fluticasone propionate. $^{14}$

It is not clear why the use of inhaled corticosteroids is not associated with a reduced decline in lung function in women. There are several possible explanations. Female sex hormones may play a role. Progesterone has steroid-like anti-inflammatory actions, ${ }^{31}{ }^{32}$ whereas oestrogens augment inflammation by influencing lymphocyte and monocyte numbers, increasing B cell differentiation and antibody production, and decreasing $\mathrm{T}$ cell suppressor activity. ${ }^{33}$ Furthermore, oestrogens enhance eosinophil adhesion to human vascular endothelial cells. ${ }^{34}$ To what extent sex hormones interfere with the response to inhaled corticosteroids in humans is as yet unknown. Women are reported to have severe asthma more frequently than men. ${ }^{2}{ }^{15}{ }^{35-38}$ However, the women in our study had similar numbers of blood eosinophils and severity of bronchial hyperresponsiveness as the men, both at initial testing and re-examination, and they had higher $\mathrm{FEV}_{1} \%$ predicted post bronchodilator and lower IgE levels at re-examination than men. Differences in asthma severity cannot therefore explain the smaller effect of inhaled corticosteroids in the women in our study. It is also unlikely that a lower prescribed dose of inhaled corticosteroids would account for the difference between the sexes as we found neither a difference in the daily dose nor in the cumulative dose of inhaled corticosteroids used by men and women. The observed lack of effect may also have been due to different airway deposition of inhaled corticosteroids in women than in men. Women have a smaller airway calibre than men, which may enhance deposition of inhaled corticosteroids in the large airways. ${ }^{39}$ This may reduce the overall beneficial effect since the current thinking is that peripheral airways contribute significantly to airway obstruction in asthma. ${ }^{40}$ Finally, women had a somewhat smaller decline in lung function before initiation of inhaled corticosteroids, although the difference between men and women was not significant. It may well be that women with a more rapid decline in lung function would have benefited from treatment with inhaled corticosteroids. This cannot be ascertained from our observations.

Our study shows a dose-response effect of inhaled corticosteroids on the annual decline in $\mathrm{FEV}_{1}$ in men. An additional analysis showed that this effect was not driven by the effect of smoking. Only $40 \%$ of the men using $\geqslant 720 \mu \mathrm{g} /$ day smoked $<5$ pack years at follow up. When women were treated with inhaled corticosteroids, no difference was seen between the effects of low or high doses. This may simply be due to the smaller number of women under study, or it might suggest that women require higher doses of inhaled corticosteroids or have lower compliance rates with maintenance treatment. It is important to clarify these issues because it is well established that inhaled corticosteroids are accompanied by side effects at high doses. Whatever the reason for the underlying differences between women and men, an important message from our results is that studies investigating the effects of inhaled corticosteroids should investigate the effects in men and women separately.

An interesting and important observation is that smoking interferes with the long term beneficial effect of inhaled corticosteroids on the decline in $\mathrm{FEV}_{1}$ in men. It has been shown previously that smoking is accompanied by a smaller clinical benefit from inhaled corticosteroids. ${ }^{16-18}$ Although the underlying mechanisms are not yet resolved, it may well be that cigarette smoking reduces histone deacetylase-2 expression and activity in the airway wall and alveolar macrophages, thereby reducing the effect of inhaled corticosteroids. ${ }^{41}$ The effect of inhaled corticosteroids in men who smoked $<5$ pack years cannot be simply explained by changes in smoking habits. Only four of the 28 men who had smoked $<5$ pack years at the end of the study were smokers at the beginning of the analyses on $\mathrm{FEV}_{1}$ decline (at age 30) and quit smoking 2-10 years before the introduction of inhaled corticosteroids. The other men were never smokers or ex-smokers and did not start or restart smoking during follow up.

In conclusion, inhaled corticosteroids are not only beneficial in asthma in the short term, but their long term use in moderate to severe adult asthma is associated with a smaller decline in $\mathrm{FEV}_{1}$ in men in a dose dependent manner. In women there was no effect on the decline in lung function. Since similar doses of inhaled corticosteroids were used in men and women, further studies are needed to investigate whether female sex hormones, airway geometry, deposition and particle size of inhaled corticosteroids, and/or differences in compliance may explain the difference in response between the sexes. Importantly, in men with $>5$ pack years of smoking, the long term beneficial effects on $\mathrm{FEV}_{1}$ decline were absent. All efforts should be made to motivate people with asthma to refrain from smoking, particularly since it prevents the long term beneficial effects of the best treatment currently available. 


\section{ACKNOWLEDGEMENTS}

The authors thank the lung function staff of Beatrixoord Haren for their effort in preparing the database on lung function which was used throughout this study.

\section{Authors' affiliations}

A Dijkstra, $\mathrm{H}$ Jongepier, Department of Pulmonary Rehabilitation, Beatrixoord, Haren, University Medical Center and University of Groningen, the Netherlands

A Dijkstra, H Jongepier, N H T ten Hacken, D S Postma, Department of Pulmonology, University Medical Center and University of Groningen, the Netherlands

J M Vonk, J P Schouten, Department of Epidemiology and Statistics, University Medical Center and University of Groningen, the Netherlands G H Koppelman, Beatrix Children's Hospital, University Medical Center and University of Groningen, the Netherlands

W Timens, Department of Pathology and Laboratory Medicine,

University Medical Center and University of Groningen, the Netherlands

This study was supported by the Netherlands Asthma Foundation (grant AF 3.2.00.38).

Competing interests: none declared.

\section{REFERENCES}

1 Peat JK, Woolcock AJ, Cullen K. Rate of decline of lung function in subjects with asthma. Eur J Respir Dis 1987;70:171-9.

2 Weiss ST, Tosteson TD, Segal MR, et al. Effects of asthma on pulmonary function in children. A longitudinal population-based study. Am Rev Respir Dis 1992; 145:58-64

3 Martin AJ, Landau LI, Phelan PD. Lung function in young adults who had asthma in childhood. Am Rev Respir Dis 1980;122:609-16.

4 Ulrik CS, Backer V, Dirksen A, et al. Extrinsic and intrinsic asthma from childhood to adult age: a 10-yr follow-up. Respir Med 1995;89:547-54

5 Kelly WJ, Hudson I, Raven J, et al. Childhood asthma and adult lung function. Am Rev Respir Dis 1988;138:26-30

6 Lange P, Parner J, Vestbo J, et al. A 15-year follow-up study of ventilatory function in adults with asthma. N Engl J Med 1998;339:1194-200.

7 Ulrik CS, Lange P. Decline of lung function in adults with bronchial asthma. Am J Respir Crit Care Med 1994;150:629-34.

8 James AL, Palmer $\mathrm{U}$, Kicic E, et al. Decline in lung function in the Busselton Health Study: the effects of asthma and cigarette smoking. Am J Respir Crit Care Med 2005;177:109-14.

9 Phelan PD, Robertson CF, Olinsky A. The Melbourne Asthma Study: 19641999. J Allergy Clin Immunol 2002;109:189-94.

10 Busse W, Elias J, Sheppard D, et al. Airway remodeling and repair. Am J Respir Crit Care Med 1999;160:1035-42.

11 Bousquet J, Jeffery PK, Busse WW, et al. Asthma: from bronchoconstriction to airways inflammation and remodeling. Am J Respir Crit Care Med 2000:161:1720-45.

12 Ten Hacken NH, Postma DS, Timens W. Airway remodeling and long-term decline in lung function in asthma. Curr Opin Pulm Med 2003;9:9-14.

13 Reed CE. The natural history of asthma in adults: the problem of irreversibility. J Allergy Clin Immunol 1999;103:539-47.

14 Convery RP, Leitch DN, Bromly C, et al. Effect of inhaled fluticasone propionate on airway responsiveness in treatment-naive individuals: a lesser benefit in females. Eur Respir J 2000;15:19-24.

15 Strachan DP, Butland BK, Anderson HR. Incidence and prognosis of asthma and wheezing illness from early childhood to age 33 in a national British cohort. BMJ 1996;312:1195-9.

16 Kerstiens HAM, Brand PLP, Hughes MD, et al. A comparison of bronchodilator therapy with or without inhaled corticosteroid therapy for obstructive airways disease. N Engl J Med 1992;327:1413-9.
17 Chalmers GW, Macleod KJ, Little SA, et al. Influence of cigarette smoking on inhaled corticosteroid treatment in mild asthma. Thorax 2002;57:226-30.

18 Pedersen B, Dahl R, Karlstrom R, et al. Eosinophil and neutrophil activity in asthma in a one-year trial with inhaled budesonide: the impact of smoking. Am J Respir Crit Care Med 1996:153:1519-29.

19 Panhuysen $\mathrm{Cl}$, Vonk JM, Koeter GH, et al. Adult patients may outgrow their asthma: a 25-year follow-up study. Am J Respir Crit Care Med 1997; 155:1267-72.

20 Panhuysen $\mathrm{Cl}$, Bleecker ER, Koeter GH, et al. Characterization of obstructive airway disease in family members of probands with asthma. An algorithm for the diagnosis of asthma. Am J Respir Crit Care Med 1998;157:1734-42.

21 de Vries K, Goei JT, Booy-Noord H, et al. Changes during 24 hours in the lung function and histamine hyperreactivity of the bronchial tree in asthmatic and bronchitic patients. Int Arch Allergy 1962;20:93-101.

22 van der Lende R, Orie NG. The MRC-ECCS questionnaire on respiratory symptoms (use in epidemiology). Scand J Respir Dis 1972;53:218-26.

23 O'Byrne PM, Pedersen S. Measuring efficacy and safety of different inhaled corticosteroid preparations. J Allergy Clin Immunol 1998;102:879-86.

24 Laird NM, Ware JH. Random-effects models for longitudinal data. Biometrics 1982;38:963-74.

25 Rijcken B, Weiss ST. Longitudinal analyses of airway responsiveness and pulmonary function decline. Am J Respir Crit Care Med 1996:154:S246-9.

26 Naumova EN. Must A, Laird NM. Tutorial in Biostatistics: Evaluating the impact of 'critical periods' in longitudinal studies of growth using piecewise mixed effects models. Int J Epidemiol 2001;30:1332-41.

27 Haahtela T, Jarvinen M, Kava T, et al. Comparison of a beta-2-agonist, terbutaline, with an inhaled corticosteroid, budesonide, in newly detected asthma. N Engl J Med 1991;325:388-92.

28 Childhood Asthma Management Program Research Group. Long-term effects of budesonide or nedocromil in children with asthma. N Engl J Med 2000;343: 1054-63.

29 Selroos $O$, Pietinalho $A$, Lofroos $A B$, et al. Effects of early vs late intervention with inhaled corticosteroids in asthma. Chest 1995:108:1228-34.

30 Haahtela $\mathrm{T}$, Jarvinen $\mathrm{M}$, Kava T, et al. Effects of reducing or discontinuing inhaled budesonide in patients with mild asthma. N Engl J Med 1994;331:700-5.

31 Hackney JF, Holbrook NJ, Grasso RJ. Progesterone as a partial glucocorticoid agonist in 1929 mouse fibroblasts: effects on cell-growth, glutamine-synthetase induction and glucocorticoid receptors. J Steroid Biochem 1981;14:971-7.

32 Svec F, Yeakley J, Harrison RW. Progesterone enhances glucocorticoid dissociation from the Att-20 cell glucocorticoid receptor. Endocrinology 1980; 107:566-72.

33 Homo-Delarche F, Fitzpatrick F, Christeff N, et al. Sex steroids, glucocorticoids, stress and autoimmunity. I' Steroid Biochem Mol Biol 1991;40:619-37.

34 Hamano N, Terada N, Maesako K, et al. Effect of sex hormones on eosinophilic inflammation in nasal mucosa. Allergy Asthma Proc 1998:19:263-9.

35 Gold DR, Rotnitzky A, Damokosh Al, et al. Race and gender differences in respiratory illness prevalence and their relationship to environmental exposures in children 7 to 14 years of age. Am Rev Respir Dis 1993:148:10-8.

36 Godden DJ, Ross S, Abdalla M, et al. Outcome of wheeze in childhood: symptoms and pulmonary function 25 years later. Am J Respir Crit Care Med 1994;149:106-12.

37 Roorda RJ, Gerritsen J, van Aalderen WM, et al. Follow-up of asthma from childhood to adulthood: influence of potential childhood risk factors on the outcome of pulmonary function and bronchial responsiveness in adulthood. $J$ Allergy Clin Immunol 1994;93:575-84.

38 Fagan JK, Scheff PA, Hryhorczuk D, et al. Prevalence of asthma and other allergic diseases in an adolescent population: association with gender and race. Ann Allergy Asthma Immunol 2001;86:177-84.

39 Esmailpour N, Hogger P, Rabe KF, et al. Distribution of inhaled fluticasone propionate between human lung tissue and serum in vivo. Eur Respir $J$ 1997; 10:1496-9.

40 Kraft M, Diukanovic R, Wilson S, et al. Alveolar tissue inflammation in asthma. Am J Respir Crit Care Med 1996;154:1505-10.

41 Barnes PJ, Ito K, Adcock IM. Corticosteroid resistance in chronic obstructive pulmonary disease: inactivation of histone deacetylase. Lancet 2004;363:731-3. 